NBER WORKING PAPER SERIES

THE FOMC VERSUS THE STAFF:

WHERE CAN MONETARY POLICYMAKERS ADD VALUE?

Christina D. Romer

David H. Romer

Working Paper 13751

http://www.nber.org/papers/w13751

\author{
NATIONAL BUREAU OF ECONOMIC RESEARCH \\ 1050 Massachusetts Avenue \\ Cambridge, MA 02138 \\ January 2008
}

This paper is an extended version of a paper presented at the American Economic Association Annual Meeting, January 5, 2008. We are grateful to David Small for assistance with the data, to Donald Kohn, David Reifschneider, Vincent Reinhart, Justin Wolfers, and Janet Yellen for helpful comments and suggestions, and to the National Science Foundation for financial support. The views expressed herein are those of the author(s) and do not necessarily reflect the views of the National Bureau of Economic Research.

NBER working papers are circulated for discussion and comment purposes. They have not been peerreviewed or been subject to the review by the NBER Board of Directors that accompanies official NBER publications.

(C) 2008 by Christina D. Romer and David H. Romer. All rights reserved. Short sections of text, not to exceed two paragraphs, may be quoted without explicit permission provided that full credit, including (C) notice, is given to the source. 
The FOMC versus the Staff: Where Can Monetary Policymakers Add Value?

Christina D. Romer and David H. Romer

NBER Working Paper No. 13751

January 2008

JEL No. E37,E52,E58

\begin{abstract}
$\underline{\text { ABSTRACT }}$
Should monetary policymakers take the staff forecast of the effects of policy actions as given, or should they attempt to include additional information? This paper seeks to shed light on this question by testing the usefulness of the FOMC's own forecasts. Twice a year, the FOMC makes forecasts of major macroeconomic variables. FOMC members have access to the staff forecasts when they prepare their forecasts. We find that the optimal combination of the FOMC and staff forecasts in predicting inflation and unemployment puts a weight of essentially zero on the FOMC forecast and essentially one on the staff forecast: the FOMC appears to have no value added in forecasting. The results for predicting real growth are less clear-cut. We also find statistical and narrative evidence that differences between the FOMC and staff forecasts help predict monetary policy shocks, suggesting that policymakers act in part on the basis of their apparently misguided information.
\end{abstract}

\author{
Christina D. Romer \\ Department of Economics \\ University of California \\ Berkeley, CA 94720-3880 \\ and NBER \\ cromer@econ.berkeley.edu \\ David H. Romer \\ Department of Economics \\ University of California \\ Berkeley, CA 94720-3880 \\ and NBER \\ dromer@econ.berkeley.edu
}


A key issue in monetary policymaking is the appropriate division of labor between the professional staff of the central bank and the appointed policymakers. Svensson (1999) argues that the appropriate role of a policymaking group, such as the Federal Open Market Committee (FOMC) in the United States, is to make judgments about social welfare, taking as given the likely outcomes of different policies as estimated by the staff. In this division, the staff is relied upon to assess current and prospective economic conditions and to forecast the likely effects of different policies. Policymakers' only role is to decide which of the various options should be chosen.

The obvious alternative is for policymakers to also play a role in forecasting and in predicting the consequences of policy actions. In this division, policymakers supplement the staff's analysis with their own information about likely economic developments and the effects of policy. Their choice of a particular policy then reflects their views not only of desired outcomes, but also of prospective developments and of the working of the economy.

Which of these divisions of labor is best clearly cannot be determined from first principles. It depends on the relative skill of the staff and the policymakers in forecasting and understanding the economy. As a result, the answer may vary across times and places.

In the United States, policymakers certainly appear to believe they have useful information to add to the staff's forecasts and estimated policy multipliers. Perhaps the strongest evidence of this comes from the transcripts of FOMC meetings. A significant portion of each meeting is devoted to the economic "go-around," where each member of the FOMC gives his or her own view of prospective conditions. Likewise, much of the discussion of appropriate policy focuses on the likely outcomes of actions, rather than on the desirability of one outcome over another. 
In this paper, we test whether American policymakers do, in fact, have useful information in one particular area - forecasting. The Board of Governors staff makes a comprehensive forecast before each FOMC meeting. In conjunction with two of these meetings each year, the Federal Reserve reports information about the forecasts of members of the FOMC for inflation, unemployment, and real growth. We compare these staff and policymaker forecasts for the period 1979-2001 with actual data to see if the FOMC forecasts contain useful information. We find that, for the most part, they do not.

We also investigate the possible consequences of the FOMC’s misguided information. In particular, we examine whether differences between the FOMC and staff forecasts help predict monetary shocks. We find suggestive statistical and narrative evidence that they do. This may indicate that the FOMC's attempts to add information to the staff forecast are not just unsuccessful, but may lead to misguided actions.

\section{Forecast Data}

The FOMC prepares forecasts twice a year, in February and July. The forecasts are contained in the Monetary Policy Report (MPR) submitted to Congress as required by the Humphrey-Hawkins Full Employment and Balanced Growth Act. We examine the forecasts of inflation, unemployment, and real growth. The forecasts in February are for inflation and growth over the four quarters ending in the fourth quarter of the current year, and for the unemployment rate in the fourth quarter of the current year. The forecasts in July are for the same variables for both the current year and the next year.

The members of the FOMC first prepare their forecasts before the FOMC meeting preceding the release of the $M P R$. In preparing these forecasts, members have access to the staff 
forecast. At the meeting, the staff presents its forecast and summarizes the members' forecasts, and the members discuss their views about the economic outlook. After the meeting, FOMC members have about a week to revise their forecasts.

The first FOMC forecasts are those in the July 1979 MPR. The forecasts of each variable are usually presented in terms of a range and a central tendency. The range shows the lowest and the highest forecasts of the individual members. The central tendency shows the lowest and highest forecasts after removal of the extremes (typically the three lowest and three highest). We use the midpoint of the central tendency as our figure for the FOMC forecast. When the central tendency is not reported, we use the midpoint of the range.

The exact variables forecast have evolved over time. For inflation, the forecasts are for the GNP implicit price deflator until July 1988, the CPI from February 1989 to July 1999, and the chain-type price index for personal consumption expenditures thereafter. For growth, the forecasts are for real GNP through July 1991 and real GDP thereafter.

The staff forecasts for the same variables are contained in the "Greenbooks" prepared roughly a week before each FOMC meeting. The Greenbooks are available only with a five-year lag. Our sample therefore ends in 2001.

When the forecasts are for variables in the National Income and Product Accounts (NIPA), such as GDP, we measure outcomes using the so-called "final” estimates, which are released roughly three months after the end of the quarter. These slightly revised data are likely to correspond most closely to what the FOMC and staff were trying to forecast. For non-NIPA variables, such as unemployment, which are not subject to consistent, immediate revisions, we measure outcomes using the data as originally released. We typically take these data from the Greenbook for the meeting following the release. 
Further details about the data are described in the Data Appendix.

\section{Does the FOMC Have Value Added in Forecasting?}

To see if the FOMC forecasts contain useful information relative to the staff forecasts, we estimate regressions of the form:

$$
\mathrm{X}_{\mathrm{t}}=\mathrm{a}+\mathrm{bS}_{\mathrm{t}}+\mathrm{cP}_{\mathrm{t}}+\mathrm{e}_{\mathrm{t}}
$$

where $\mathrm{X}$ is the realized value of some variable, such as inflation, and $\mathrm{S}$ and $\mathrm{P}$ are the staff and policymaker (FOMC) forecasts of that variable. Since the members of the FOMC know the staff forecasts when they prepare their forecasts, the hypothesis that the FOMC forecasts are rational predicts $\mathrm{a}=\mathrm{b}=0, \mathrm{c}=1$. Our focus, however, is on the narrower question of whether the FOMC forecasts contain useful information relative to the staff's. Thus, our main interest is in whether c is positive. That is, conditional on the staff's forecast, does the variable being forecast on average turn out higher when the FOMC's forecast is higher?

The structure of the forecasts suggests that the residuals in (1) are unlikely to be i.i.d. The forecast horizons range from less than six months to well over a year, and not all realized values for earlier forecasts are known when a forecast is made. Thus, the residuals are likely to exhibit both heteroskedasticity and serial correlation.

We therefore estimate the regression in two ways. First, as a baseline, we use ordinary least squares (OLS) and compute conventional OLS standard errors. Second, we employ weighted least squares (WLS). The variance of e is allowed to depend on whether the forecast is a February forecast, a July forecast for the current year, or a July forecast for the next year; the three variances are estimated from the data. For the WLS estimates, we compute Newey-West 
standard errors with three lags (which is the maximum lag at which one would expect any serial correlation).

The results are given in Table 1 . The most striking finding is for inflation. The OLS estimates suggest that someone trying to predict inflation who had access to both the staff and FOMC forecasts should put a coefficient of $1.10(\mathrm{t}=2.82)$ on the staff forecast and a coefficient of $-0.10(\mathrm{t}=-0.28)$ on the FOMC forecast. This suggests that the FOMC forecast does not contribute useful information. Indeed, the fact that the coefficient on the FOMC forecast is negative (albeit not significantly so) suggests that someone trying to forecast inflation should move away from the FOMC forecast, not toward it. Taking into account the likely heteroskedasticity and serial correlation of the residuals only strengthens the results. The WLS estimates with robust standard errors show that the weight on the staff forecast in predicting inflation is $1.40(\mathrm{t}=5.54)$ and that on the FOMC forecast is more negative and close to significant.

The results for unemployment are similar to those for inflation. In this case, the OLS estimates suggest putting a weight of essentially one $(\mathrm{t}=2.52)$ on the staff forecast and a weight of virtually zero on the FOMC forecast. The estimates using WLS and robust errors raise the weight on the FOMC forecast slightly, but it remains small and very far from significant.

For real growth, the results are slightly supportive of the FOMC having useful information. The OLS estimates indicate weights of 0.25 on the staff forecast and 0.63 on the FOMC forecast. Neither weight, however, is significantly different from zero. Correcting for heteroskedasticity and serial correlation has little effect on the point estimates, but makes the standard errors considerably larger.

In largely failing to add value to the staff forecast, the FOMC is in good company. 
Romer and Romer (2000) find that someone trying to forecast economic outcomes who had access to both the Greenbook and a range of high-profile commercial forecasts should put little or negative weight on the commercial forecasts. FOMC members, however, have a key advantage over commercial forecasters: access to the Greenbook. Thus, at the very least, they could make forecasts that differed only trivially from the staff's. In this case, the FOMC and staff forecasts would be nearly collinear, and the coefficients could not be estimated with any precision. To a considerable extent, this is what is occurring with the forecasts of real growth.

The FOMC should be able not just to match the staff, however, but to do better. Because policymakers are allowed to revise their forecasts after the FOMC meeting where the forecasts are discussed, they have a potential data advantage of up to two weeks. Likewise, FOMC members are less constrained than the staff in what they can assume about future policy actions. The fact that for inflation and unemployment, the coefficient on the staff forecast is large and significant while that on the FOMC forecast is effectively zero implies not just that FOMC members fail to add information, but that their efforts to do so are counterproductive.

One question is whether the usefulness of the FOMC forecasts has changed over time. It is possible, for example, that as the FOMC has come to include more economists and professional forecasters, the value of its information has increased. We test for this possibility by estimating the regressions separately for the two halves of the sample. The first covers the forecasts from July 1979 to July 1990; the second covers those from February 1991 to July 2001.

The results do suggest a change over time. ${ }^{\square}$ For inflation, the weights on the staff and FOMC forecasts for the first half of the sample are $1.54(\mathrm{t}=2.46)$ and $-0.54(\mathrm{t}=-0.89)$, respectively; for the second half, they are $0.84(\mathrm{t}=1.94)$ and $-0.22(\mathrm{t}=-0.42)$. The results for the unemployment rate show a similar move toward the FOMC having more useful information

\footnotetext{
${ }^{1}$ We focus on the OLS estimates for simplicity. The WLS results are similar.
} 
over time. The weights on the staff and FOMC forecasts change from $1.59(\mathrm{t}=2.16)$ and -0.66 $(\mathrm{t}=-0.87)$ to $0.51(\mathrm{t}=1.31)$ and $0.35(\mathrm{t}=0.88)$. The change for the real growth regressions is more dramatic. The weights on the staff and FOMC forecasts for the first half of the sample are $0.86(\mathrm{t}=1.21)$ and $-0.03(\mathrm{t}=-0.04)$, respectively; for the second half they are $-0.81(\mathrm{t}=-1.17)$ and $1.74(\mathrm{t}=2.45)$. For real growth the FOMC appears to have had no useful information before 1991, but significant useful information in more recent years.

As a check on our analysis, we examine the importance of outliers. Figure 1 shows the partial association between the actual series and the FOMC forecast for each variable for the full sample. ${ }^{2}$ The three panels show that there are fairly few obvious influential observations. ${ }^{\text {Q }}$ One that shows up in each case as damaging the FOMC's predictive power is the observation for the next-year forecast corresponding to the FOMC meeting in July 1981. When we exclude this observation, the results for inflation are little changed; those for the unemployment rate move slightly toward the FOMC having some useful information; and those for real growth move strongly in favor of the FOMC. Another observation that could be damaging the FOMC's apparent predictive power for inflation, but not for unemployment or real growth, is that corresponding to the FOMC meeting in February 1990. Excluding this observation does not in any way rescue the hypothesis that the FOMC inflation forecast contains useful information: the weights for this sample are $0.95(t=2.55)$ on the staff forecast and $0.03(t=0.09)$ on the FOMC forecast. From these and other exercises, we conclude that the results in Table 1 reflect consistent patterns in the data. The FOMC's attempts to improve on the Greenbook forecasts,

\footnotetext{
${ }^{2}$ That is, for each variable we regress both the FOMC forecast and the actual value on the Greenbook forecast and a constant, and then do a scatter plot of the residuals.

3 The absence of obvious outliers does not mean that the differences between the FOMC and staff forecasts are small. The residuals of the regression of the FOMC forecast on the staff forecast for the three variables shown along the horizontal axes are not tightly bunched around the origin. Likewise, if one looks directly at the forecast differences, one finds substantial variation. The standard deviations of the forecast differences are 0.28 for inflation; 0.23 for unemployment; and 0.35 for real growth.
} 
with the partial exception of the forecasts for real growth, have been largely unsuccessful.

Our results show that in constructing its forecasts, the FOMC is not using the information in the staff forecasts effectively. One might nevertheless be interested in the relative accuracy of the FOMC and staff forecasts. Relative accuracy depends on two factors: how the realized value of the variable being forecast moves on average with the two forecasts, and the average bias of the forecasts. The first factor is shown by our regressions. With regard to bias, both the FOMC and the staff have been overly pessimistic on average about all three variables, with the FOMC being more biased for inflation and the staff being more biased for unemployment and real growth. The average forecast error (actual value minus forecast) for inflation is -0.38 $(\mathrm{t}=-3.62)$ for the FOMC and $-0.25(\mathrm{t}=-2.49)$ for the staff. For unemployment, the average errors are $-0.09(\mathrm{t}=-0.94)$ for the FOMC and $-0.15(\mathrm{t}=-1.76)$ for the staff. For growth, they are $0.10(t=0.60)$ for the FOMC and $0.22(t=1.26)$ for the staff.

To assess overall forecast accuracy, we compute the mean squared errors (MSEs) of the various forecasts. For inflation, where both the regression weights and the biases favor the staff, the MSE is 0.89 for the FOMC and 0.71 for the staff. For unemployment, where the weights and biases work in opposite directions, the MSE is 0.57 for the FOMC and 0.54 for the staff. And for real growth, where both factors slightly favor the FOMC, it is 1.99 for the FOMC and 2.10 for the staff. Thus, although the FOMC is not using its available information optimally, even for inflation its forecasts are not dramatically less accurate than the staff's. Nonetheless, the difference in the MSEs of the inflation forecasts is highly significant. The differences in the MSEs for the other variables, in contrast, are far from significant. . $^{-1}$

\footnotetext{
${ }^{4}$ We assess statistical significance by running regressions of the form $\left(e^{\mathrm{P}}\right)^{2}-\left(\mathrm{e}_{\mathrm{t}}^{\mathrm{S}}\right)^{2}=\mathrm{c}+\mathrm{u}_{\mathrm{t}}$, where $\mathrm{e}^{\mathrm{P}}$ and $\mathrm{e}^{\mathrm{S}}$ are the FOMC and staff forecast errors, and examining the significance of $\mathrm{c}$.
} 


\section{Do Forecast Differences Affect Policy Choices?}

The failure of the FOMC to bring useful additional information to the monetary policymaking process raises an obvious question: do policymakers act on their apparently useless information? To put it even more bluntly, are the FOMC's efforts to improve on the staff forecasts just ineffective, or are they a source of monetary policy mistakes?

To investigate this issue, we test whether the difference between the FOMC and staff forecasts of key variables is a significant predictor of monetary policy shocks. As our measure of shocks, we use the series derived in Romer and Romer (2004). This derivation involved reading the narrative record to identify what policymakers intended to happen to the federal funds rate after each FOMC meeting. We then regressed the intended changes in the funds rate on the Greenbook forecasts of inflation, real growth, and the unemployment rate. Our shock series is the residuals of this regression. It shows times when the FOMC moved the funds rate in a way that differed from its usual response to the staff forecast. One possible source of such unusual movements is differences between the FOMC and staff forecasts.

To see if this is the case, we run regressions of the form:

$$
\mathrm{M}_{\mathrm{t}}=\mathrm{a}+\mathrm{b}\left(\mathrm{P}_{\mathrm{t}}-\mathrm{S}_{\mathrm{t}}\right)+\mathrm{e}_{\mathrm{t}}
$$

where $\mathrm{M}$ is our measure of monetary policy shocks, and $\mathrm{P}$ and $\mathrm{S}$ are again the FOMC and staff forecasts of some variable. We consider the impact of the forecast differences for each variable (inflation, unemployment, and real growth) first individually and then in combination. For the July meetings, when we have FOMC forecasts for both the current year and the next year, we 
measure $\mathrm{P}$ and S using FOMC and staff forecasts only for the current year.

The results are given in Table 2. The estimates suggest that forecast differences may be one source of monetary shocks. When the differences for each variable are considered separately, the estimated impact on monetary policy is of the expected sign and marginally significant. The point estimates suggest a relatively large impact. For example, the estimates for inflation in row (1) show that an FOMC forecast of inflation one percentage point higher than the staff forecast is associated with an unusual rise in the federal funds rate of approximately 30 basis points. Similarly, an FOMC forecast of the unemployment rate one percentage point higher than the staff forecast is associated with an unusual fall in the federal funds rate of 50 basis points.

The results in row (4) show the effect when the forecast differences for all three variables are included. The point estimates and the statistical significance fall somewhat, but are qualitatively unchanged. These results suggest that the forecast differences may combine to generate even larger monetary shocks. For instance, if the FOMC is more pessimistic than the staff about inflation and more optimistic about unemployment and real growth, a combination that could plausibly occur, the coefficients predict a substantial unusual rise in the funds rate.

Figure 2 shows a scatter plot of the difference between the FOMC and the staff forecasts of inflation and the monetary shock series. The figure indicates three FOMC meetings where the gap between the FOMC and staff forecasts was especially large, and where the FOMC's behavior was consistent with the pattern suggested by the regressions. At two of the meetings, in July 1979 and February 1982, the FOMC's inflation forecast was well above the staff's, and there were substantial contractionary monetary shocks. At the third, in February 1991, the FOMC's inflation forecast was well below the staff's, and there was a substantial expansionary

\footnotetext{
${ }^{5}$ Because the shock series ends in 1996, the sample period for these regressions is 1979-1996.
} 
shock. We examine the transcripts of these three meetings to see if the statistical relationship may be capturing a genuine behavioral link.$^{6}$

In the July 1979 episode, FOMC members emphasized their differences from the staff forecast and urged short-run policy actions consistent with these differences. For example, Governor Wallich said: "I continue to think that we may be underestimating inflation" (Transcript, 7/11/79, p. 15), and urged raising the top of the funds rate target range to allow for tightening if the price of the dollar fell in the coming weeks (p. 42). Likewise, Mr. Mayo said: "Although the staff forecast is a reasonable one, I find myself a little more pessimistic. I am concerned about both the likelihood of less real growth and more inflation” (pp. 20-21). He urged keeping the funds rate at its same, relatively high level (p. 44). The discussion clearly suggests that gloomier forecasts of inflation than the staff were one reason the FOMC voted to keep policy tight despite high unemployment and fear of a recession.

The second of these episodes, February 1982, is less supportive of a causal link between the forecast differences and monetary shocks. While members clearly noted their disagreement with the staff forecast, these differences do not appear to have been central to their actions. Money growth had been enormous in the previous month, and much of the meeting revolved around policymakers' view of what would happen to velocity. The increase in the funds rate target seemed to be the result of an attempt to keep money growth rates in the target ranges.

In the third episode, February 1991, policymakers clearly overruled the staff on the forecast and acted on the basis of their own views. In the go-around, member after member said the staff forecast was too optimistic about real growth and predicted that inflation would be lower than the staff forecast as a result. Chairman Greenspan summarized the committee’s view

\footnotetext{
${ }^{6}$ Actual inflation in 1979 and 1982 was closer to the staff forecast than to the FOMC forecast, while in 1991 it was closer to the FOMC forecast. Thus, the three episodes fit with our overall finding that the FOMC does not on average improve on the staff forecast.
} 
by saying: “And while we've all taken pot shots at the Greenbook forecast, it is not a zero probability forecast by any means” (Transcript, 2/6/91, p. 49). He went on to say: "I actually don't quite agree with the Greenbook because I think the inflation forecast is too high. From what I can sense, looking at the internal price structure of a lot of companies and talking to a lot of people ..., it may turn out to be doing better” (p. 49). This belief led Greenspan to conclude: “[W]e may have to move it [the interest rate structure] down further as insurance” (p. 49). Other members also drew the link between their differences from the staff forecast and their view of appropriate policy. For example, Mr. Boehne said: “I think the staff forecast, while well thought out, is on the rosy side. ... I'd rather err on the side of too much stimulus at this point rather than too little” (p. 24).

Thus, the narrative evidence, like the statistical analysis, is suggestive of a link between forecast differences and monetary policy actions. It appears that monetary policymakers may indeed act on information that is of little or negative value.

\section{Conclusions}

When it comes to forecasting, monetary policymakers in the United States do not have useful information relative to their staff. Someone wishing to predict inflation and unemployment who had access to the forecasts of both the FOMC and the staff would be well served by discarding the FOMC forecast and just using the staff predictions. Since the staff forecast reflects a great deal of effort by hundreds of highly trained professionals, the finding that policymakers do not have useful additional information is not especially surprising. But since policymakers know the staff forecast when they make theirs, the finding that the staff forecast clearly contains information beyond what is in policymakers' forecast indicates that the FOMC 
is not using its available information optimally in constructing its forecast.

Yet, as the FOMC currently operates, policymakers' forecasts play a role in policy. Much time is spent preparing individual forecasts and debating the staff forecast. More importantly, we find suggestive statistical and narrative evidence that differences between the FOMC and staff forecasts are one source of monetary policy shocks. Policymakers appear to base at least some decisions on their apparently useless information.

These findings suggest that a more effective division of labor within the Federal Reserve might be for the staff to present policymakers with policy options and related forecasted outcomes, and for policymakers to take those forecasts as given. With this division, the role of the FOMC would be to choose among the suggested alternatives, not to debate the likely outcome of a given policy.

Finally, monetary policymakers in many countries are less likely to be experts than in the United States. This suggests that the likelihood that they will have useful information is even smaller than for the FOMC. For this reason, monetary policymakers elsewhere might wish to consider the possibility that they do not have additional information, and to encourage empirical testing of this proposition. 


\section{Data Appendix}

The FOMC Forecasts. The FOMC's forecasts are presented in its Monetary Policy Reports (MPRs) to the Congress, which have been submitted each February and July since 1979. The MPRs are reprinted in both the Federal Reserve Bulletin and the Board of Governors Annual Report. They are available on-line back to the July 1996 MPR.

Four variables are always forecast: nominal growth, real growth, inflation, and unemployment. Growth rates are always fourth quarter to fourth quarter (Q4 to Q4), and the unemployment rate is always for $\mathrm{Q} 4$. In the February $M P R$, the forecasts are for the current year only. In the July $M P R$, they are for the current year and the next year.

From the February 1983 MPR to the present, the forecasts are reported in terms of "ranges" and "central tendencies." It is fairly clear that the ranges go from the lowest to the highest forecast. When the "Chart Shows" (see below) explain the central tendencies, they almost always say that they are obtained by dropping the three lowest and the three highest forecasts. (The Chart Show preceding the February 1994 MPR says that those central tendencies are obtained by dropping only the lowest and highest two. There are also occasional references to rounding in the Chart Shows.)

The first two MPRs that have forecasts say (or imply) that the forecasts are the Board's and not the full FOMC's; the next five are not clear about whether the forecasts incorporate the views of the Reserve Bank presidents who are not voting members of the FOMC. In addition, the first seven MPRs only give ranges. The language varies, sometimes implying that they are full ranges and sometimes that they are central tendencies.

The members first prepare their forecasts prior to the FOMC meeting that precedes the submission of the $M P R$. Our understanding is that they have already received the Greenbook for the upcoming meeting by the time they prepare their forecasts. The members are allowed to revise their forecasts between the meeting and the time the $M P R$ is completed. (We do not know whether they have always been allowed to do this, but they certainly have for a long time.)

The staff presentation (known as the "Chart Show") at the FOMC meeting preceding the $M P R$ often includes a chart summarizing the members' forecasts. The forecasts presented in the Chart Shows are often not in exactly the same terms as the forecasts in the MPRs. Sometimes the forecasts are for annual averages; early on, they are presented separately for Governors and Presidents; and the like. And, because the members can revise their forecasts after the meeting, even when the forecasts are of exactly the same thing, the forecasts in the Chart Show often differ from the forecasts in the $M P R$.

The exact variables forecast have changed over time. The first $M P R$, in February 1979, contained no forecasts. From July 1979 to July 1988, the MPRs forecast nominal GNP growth, real GNP growth, inflation measured using the GNP deflator, and the unemployment rate. (The February 1980 MPR also forecast employment growth and CPI inflation. This is the only time additional variables have been forecast.) The inflation variable switched to the CPI (CPI-U) in the February $1989 M P R$, and then to the PCE chain-type price index in the February $2000 M P R$. The switch from GNP to GDP for nominal and real growth occurred in the February $1992 M P R$. In addition, the real growth measure changed base years, and then changed to chain-weighted, as the Bureau of Economic Analysis (BEA) switched its measure.

The unemployment rate forecast has almost always been the civilian unemployment rate. For the MPRs from February 1983 through February 1986, however, it is not clear whether it 
was the civilian unemployment rate or the unemployment rate including members of the armed forces stationed in the United States (which is typically a tenth of a percentage point lower) that was being forecast. It is clear that the Greenbooks used the civilian unemployment rate throughout (this can be seem by looking at the figures in the Greenbooks for the actual unemployment rate). The $M P R$ s for this period generally do not specify the exact unemployment concept being forecast. Two (February 1983 and February 1986) indicate that the FOMC's forecast is for the overall unemployment rate, and one (July 1985) indicates that it is for the civilian unemployment rate.

We have examined some transcripts from this period and found no discussion of this issue. Our guess is that there was little concern about it. For example, it is possible that the FOMC members were simply asked to prepare forecasts of the unemployment rate, without the exact concept being specified, and that the occasional notes in the MPRs specifying which unemployment concept was being forecast were added when the $M P R$ s were being prepared. Given that it is clear from the Greenbooks that the Federal Reserve focused on the civilian unemployment rate throughout, we interpret the FOMC forecasts as being of that rate in all cases.

The Staff Forecasts. We take our figures for the staff forecasts from the Greenbook prepared for the FOMC meeting at which the members' forecasts and the $M P R$ were discussed. The Greenbook is typically prepared about a week before the FOMC meeting. When the cover sheet of the forecast presents a figure for the exact variable being forecast (such as Q4 to Q4 real GNP growth), we use that figure. When it does not, we compute it from the detailed forecast tables.

The charts presenting the FOMC forecasts also give the staff's forecasts of the same variables. With a few small exceptions (which we believe are typographical errors), these numbers agree with what is in the Greenbook for the same meeting. As noted above, however, we use the figures from the Greenbooks in all cases.

The Greenbooks from year $t$ are released at the end of year $t+5$. Thus, the latest Greenbooks currently available are those from 2001.

Outcomes. For NIPA variables (nominal and real GNP and GDP growth, and inflation measured by the implicit GDP deflator or the PCE chain-type price index), we use the BEA's "final" estimates. This version of the data includes the two very rapid revisions the BEA does of each series. The Q4 final estimates are typically released in March, and are first published in the March or April issue of the Survey of Current Business. We compute percentage changes using numbers from the same issue of the Survey. For example, our figure for real GDP growth in 1999 is computed as the percentage change in the estimates of real GDP from 1998Q4 to 1999Q4 from the April 2000 Survey.

For the CPI and the unemployment rate, our figures for outcomes are those first reported by the Bureau of Labor Statistics (BLS). Since the BLS did not construct its own quarterly averages of monthly figures for much of our sample, we use the figures for actual Q4 to Q4 CPI inflation and the actual Q4 unemployment rate from the first Greenbook prepared after the release of the December data. This is always the Greenbook prepared in late January or the very beginning of February. Since the last publicly available Greenbook is for the end of 2001, we take our figures for actual unemployment in 2001Q4 and 2002Q4 from the first issues of the Monthly Labor Review that report the unemployment rate for December of the corresponding 
year.

Our outcome measures correspond as closely as possible to the measures being forecast. For example, the July 1988 MPR forecast inflation for 1989 measured by the GNP deflator, while the February 1989 and July 1989 MPRs forecast inflation for 1989 measured by the CPI. We therefore use 1989 inflation measured by the deflator as the outcome corresponding to the first forecast, and 1989 inflation measured by the CPI as the outcome corresponding to the other two forecasts. (One case where we cannot make the concepts line up exactly involves changes in base years. For example, the February 1995 MPR forecast real growth in 1995 as measured by real GDP in 1987 dollars. By the time the final estimates of 1995Q4 real GDP were released in early 1996, however, the BEA had switched to reporting chain-weighted real GDP, and no longer reported real GDP in 1987 dollars.) 


\section{$\underline{\text { References }}$}

Board of Governors of the Federal Reserve System. Monetary Policy Report. Various issues.

Board of Governors of the Federal Reserve System. Federal Open Market Committee Transcripts. Various meetings.

Romer, Christina D., and David H. Romer. "Federal Reserve Information and the Behavior of Interest Rates.” American Economic Review, June 2000, 90(3), pp. 429-57.

Romer, Christina D., and David H. Romer. "A New Measure of Monetary Shocks: Derivation and Implications.” American Economic Review, September 2004, 94(4), pp. 1055-84.

Svensson, Lars E. O. “Inflation Targeting as a Monetary Policy Rule.” Journal of Monetary Economics, June 1999, 43(3), pp. 607-54. 
Table 1

Role of Staff and FOMC Forecasts in Predicting Actual Values

\begin{tabular}{|c|c|c|c|c|}
\hline Inflation & $\underline{\text { Constant }}$ & $\underline{\text { Staff Forecast }}$ & $\underline{\text { FOMC Forecast }}$ & $\underline{\mathrm{R}^{2}}$ \\
\hline (1) OLS & $-0.20(0.22)$ & $1.10(0.39)$ & $-0.10(0.37)$ & 0.86 \\
\hline (2) WLS & $-0.26(0.11)$ & $1.40(0.25)$ & $-0.38(0.25)$ & 0.93 \\
\hline \multicolumn{5}{|c|}{ Unemployment } \\
\hline (3) OLS & $0.26(0.41)$ & $0.97(0.38)$ & $-0.03(0.40)$ & 0.79 \\
\hline (4) WLS & $0.21(0.38)$ & $0.78(0.37)$ & $0.17(0.34)$ & 0.89 \\
\hline \multicolumn{5}{|l|}{$\underline{\text { Real Growth }}$} \\
\hline (5) OLS & $0.43(0.36)$ & $0.25(0.49)$ & $0.63(0.52)$ & 0.44 \\
\hline (6) WLS & $0.52(0.58)$ & $0.17(0.88)$ & $0.67(0.90)$ & 0.50 \\
\hline
\end{tabular}

Notes: The dependent variable is the actual value of the variable being forecast. Standard errors are in parentheses. The weighted least squares regressions use Newey-West standard errors. 
Table 2

Role of Forecast Differences in Predicting Monetary Policy Shocks

\begin{tabular}{|c|c|c|c|c|c|}
\hline & \multicolumn{5}{|c|}{ Difference between FOMC and Staff Forecast for: } \\
\hline & Constant & Inflation & Unemployment & Real Growth & $\underline{\mathrm{R}^{2}}$ \\
\hline (1) & $0.04(0.06)$ & $0.31(0.20)$ & & & 0.07 \\
\hline$(2)$ & $0.04(0.06)$ & & $-0.50(0.25)$ & & 0.11 \\
\hline (3) & $0.03(0.06)$ & & & $0.31(0.16)$ & 0.11 \\
\hline (4) & $0.01(0.06)$ & $0.23(0.21)$ & $-0.35(0.31)$ & $0.13(0.20)$ & 0.17 \\
\hline
\end{tabular}

Notes: The dependent variable is the Romer and Romer (2004) measure of monetary shocks. Standard errors are in parentheses. 


\section{Figure 1}

Partial Association of FOMC Forecasts and Actual Values

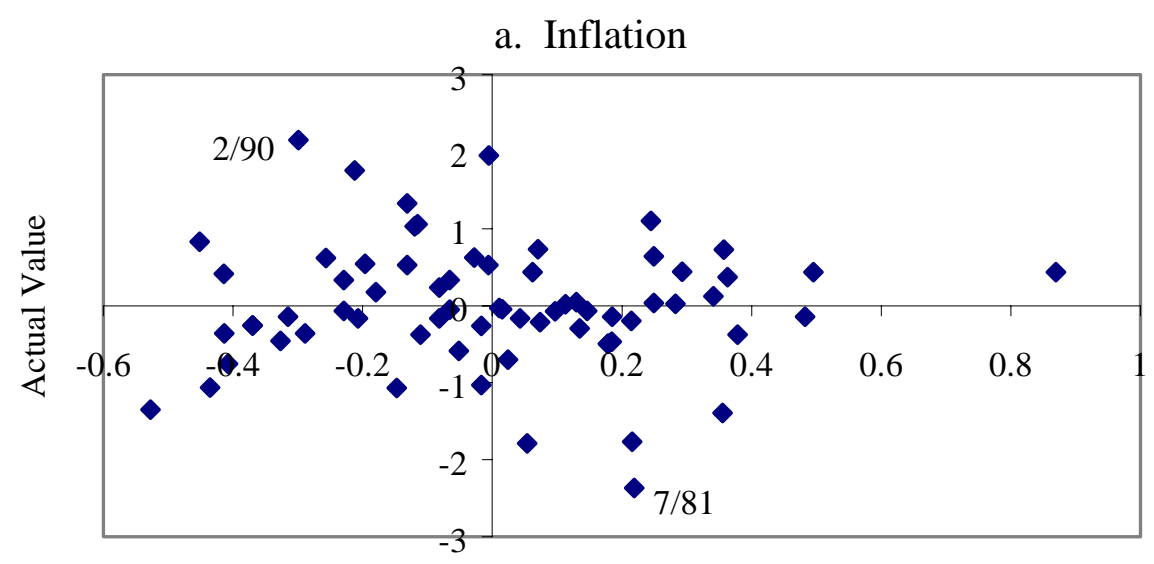

FOMC Forecast

b. Unemployment

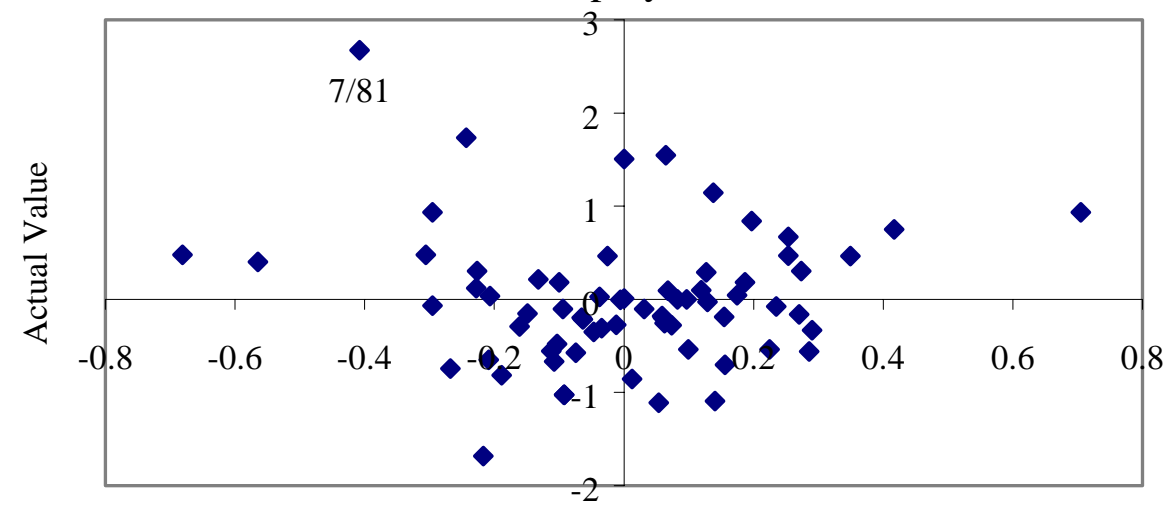

FOMC Forecast

c. Real Growth

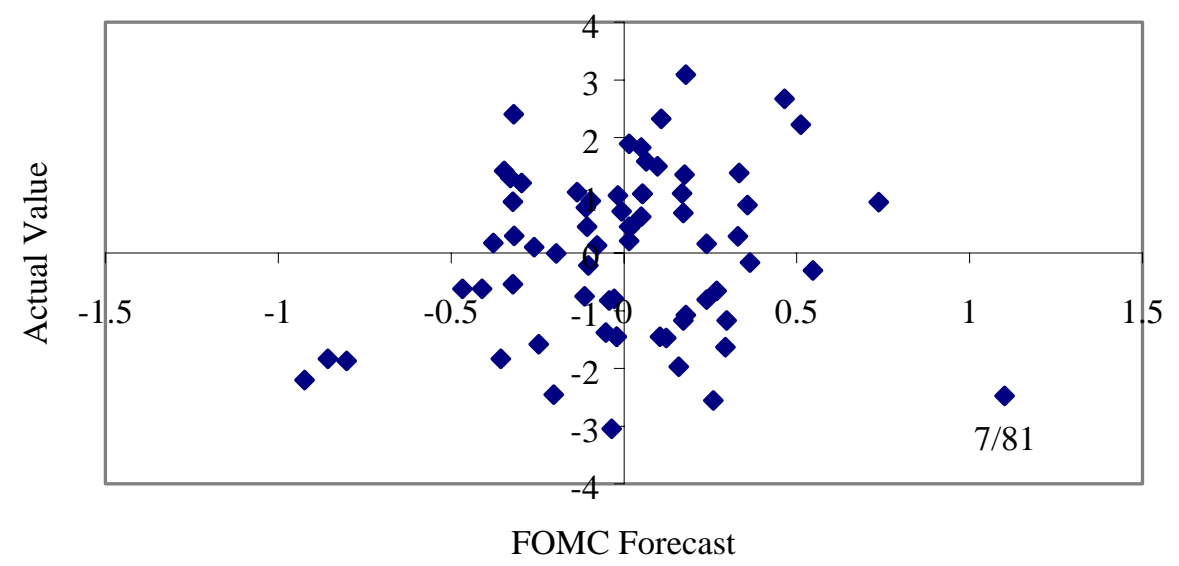


Figure 2

Scatter Plot of Inflation Forecast Differences and Monetary Policy Shocks

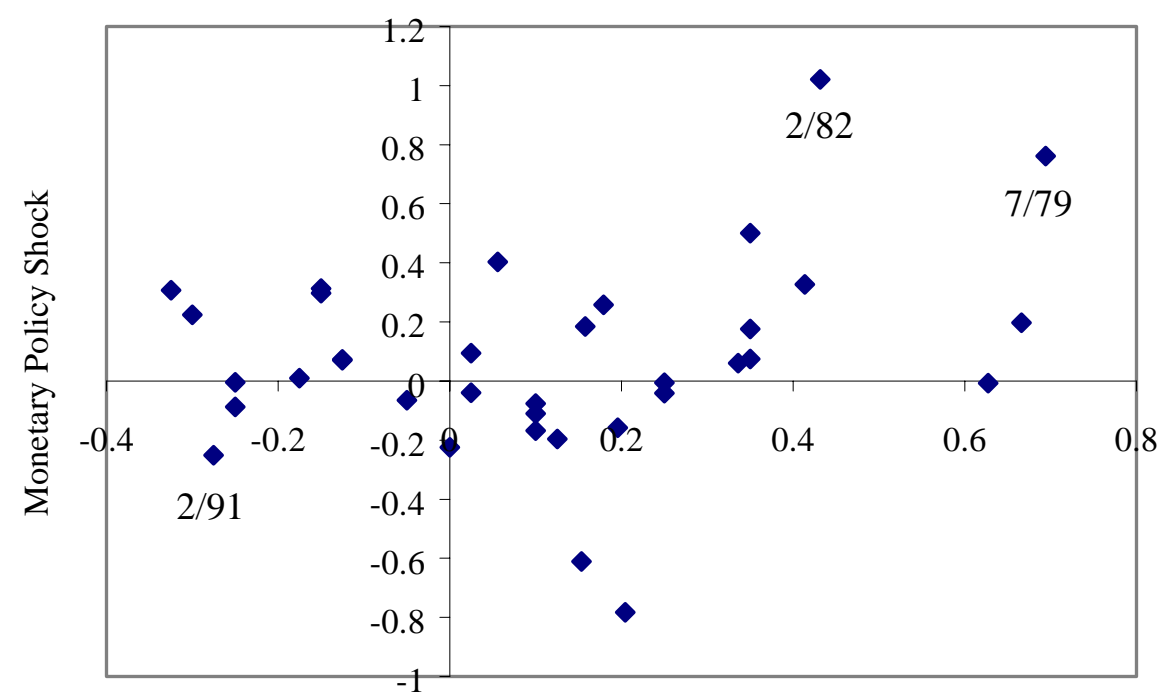

Forecast Difference 